\title{
EFEITO DA INJEÇÃO DE DIFERENTES CONCENTRAÇÕES DE CLORETO DE CÁLCIO NA TEXTURA E ACEITABILIDADE DE CARNE BOVINA MATURADA ${ }^{1}$
}

\author{
Riana Jordão Barrozo HEINEMANN ${ }^{2}$, Marcos Franke PINTO 2*
}

\begin{abstract}
RESUMO
A maturação a vácuo é uma das alternativas tecnológicas mais utilizadas para melhorar e padronizar a textura da carne bovina. Nesse processo, o amaciamento decorre da ação de enzimas proteolíticas endógenas, dentre as quais se destacam as calpaínas, cuja atividade depende da presença de íons cálcio livres no sarcoplasma. Por isso, a adição de soluções de cloreto de cálcio promove um incremento na proteólise durante a maturação. No entanto, dependendo da concentração, esse sal pode causar a formação de sabor desagradável. Assim, neste trabalho, avaliou-se o efeito da adição, na razão de $5 \%$ (v/p), de soluções 100,200 e $300 \mathrm{mM}$ de $\mathrm{CaCl}_{2}$, seguida de maturação por 14 dias, na proteólise, maciez e sabor de amostras de carne bovina (m. Longissimus dorsi). A fragmentação miofibrilar foi intensificada e a força de cisalhamento diminuída pelo aumento da concentração salina. O efeito da concentração de cloreto de cálcio sobre a aceitabilidade das amostras foi melhor representado por uma curva de resposta de efeito quadrático, cuja equação indicou que a concentração mais adequada para a aplicação desse procedimento tecnológico é de $181,14 \mathrm{mM}$. Os resultados obtidos demonstram que a adição de solução de cloreto de cálcio, seguida de maturação, representa uma possibilidade tecnológica para melhoria de qualidade de carne bovina in natura.

Palavras-chave: carne; maciez; maturação.
\end{abstract}

\section{SUMMARY}

EFFEET OF DIFFERENT CONCENTRATION OF CALCIUM CHLORIDE IN TEXTURE AND ACEITABILITY OF AGED BEEF. Vacuum aging is one of the technological alternatives to improve and standard beef texture. In this process, the tenderization derives from endogenous proteolytic enzymes action, where calpains are involved and their activity is dependent on the level of free calcium in the sarcoplasm. The direct addition of calcium increases proteolysis during aging, but in some concentrations may cause off-flavor. This work evaluated the effect of addition, on a $5 \%(\mathrm{v} / \mathrm{w})$ basis, of 100,200 and $300 \mathrm{mM}$ of $\mathrm{CaCl}_{2}$ solutions followed by vacuum aging for 14 days, on fragmentation, tenderness and taste of beef samples (m. Longissimus dorsi $)$. Myofibril fragmentation increased and shear force decreased with increasing calcium chloride concentration. The effect of calcium chloride addition on sensory evaluation scores was best explained by a quadratic equation, indicating $181,14 \mathrm{mM}$ as the best solution concentration. The results demonstrated that calcium chloride solution addition, followed by vacuum aging, is a technological alternative to improve beef quality traits.

Keywords: beef; tenderness; aging.

\section{1 - INTRODUÇÃO}

Dentre os fatores que influenciam a qualidade da carne bovina in natura, a maciez exerce papel fundamental. Esse atributo é influenciado por uma complexa variedade de fatores e, em decorrência disso, a textura só é conhecida no momento do consumo, fato que representa um importante problema para a indústria cárnea [17]. Esse problema é bastante acentuado no Brasil, devido a vários fatores, como a elevada idade dos animais abatidos, o manejo pré e pós-abate, o estado nutricional dos animais e o fato dos rebanhos serem constituídos predominantemente por raças zebuínas [1]. Uma das alternativas tecnológicas mais difundidas e utilizadas pelas indústrias nacionais para melhorar e padronizar a textura é a maturação de cortes cárneos embalados a vácuo sob refrigeração. Esse processo retarda o crescimento microbiano e possibilita a ação de proteases endógenas.

De acordo com JOHNSON et al. [9], o principal responsável pela proteólise, que provoca a degradação da estrutura muscular pós-abate e o conseqüente amaciamento da carne, é o sistema formado pela enzima calpaína, que é ativada pelos íons cálcio presentes no

1. Recebido para publicação em 28/06/2002. Aceito para publicação em 16/07/2003 (000920).

2. Departamento de Apoio, Produção e Saúde Animal - UNESP / Araçatuba-SP *mfpinto@fmva.unesp.br

* A quem a correspondência deve ser enviada. citoplasma da célula muscular, e pela calpastatina, uma proteína que age como inibidor. A calpaína se apresenta sob as formas de calpaína I e II [11]. A primeira necessita de 1 a $5 \mathrm{mM}$ de cálcio para se ativar. Já a calpaína II necessita de uma concentração de cálcio livre em torno de 50 a $70 \mathrm{mM}$, quantidades maiores do que as encontradas naturalmente na carne [9]. Como conseqüência, apenas 30\% da calpaína II é ativada num processo natural de maturação [5]. A fim de melhorar a eficiência desse sistema, vem sendo estudada a adição de soluções salinas contendo íons cálcio $\left(\mathrm{CaCl}_{2}\right)$ à carne, seguido de maturação a vácuo sob refrigeração [2, $13,19]$. O tempo geralmente utilizado para essa maturação varia de 7 a 14 dias $[10,12,18]$.

Além do tempo de maturação, é importante que a injeção de cloreto de cálcio seja realizada após a instalação do rigor mortis, uma vez que a carne tratada em estado pré-rigor pode apresentar problemas de aparência e flavor [19]. Além disso, dependendo da quantidade de sal adicionado à carne, pode ocorrer formação de sabor indesejável. MORGAN et al. [14] observaram o desenvolvimento de sabor amargo e metálico em carne injetada com solução $300 \mathrm{mM}$ de cloreto de cálcio. Assim, é importante estabelecer a concentração e quantidade ideal de $\mathrm{CaCl}_{2}$ a ser adicionado à carne para obter o efeito desejado de abrandamento da textura, sem promover o surgimento de defeitos de sabor decorrentes da aplicação dessa alternativa tecnológica. Para 
isso, neste trabalho, amostras de carne bovina (m. Longissimus dorsi) foram submetidas à maturação por 14 dias, após adição de soluções de cloreto de cálcio em três diferentes concentrações $(100,200$ e 300mM), avaliando-se o efeito desse procedimento na proteólise enzimática, amaciamento e sabor do produto.

\section{2 - MATERIAL E MÉTODOS}

\section{1 - Animais}

As amostras de carne utilizadas neste trabalho foram retiradas da meia carcaça esquerda de 10 novilhos Nelore, apresentando até 4 dentes da $2^{\text {a }}$ dentição, conformação retilinea, gordura de cobertura uniforme e peso de carcaça acima de $210 \mathrm{~kg}$. Os animais foram abatidos no Frigorífico Bertin Ltda., localizado em Lins - SP, segundo as normas do Serviço de Inspeção Federal [3].

\section{2 - Obtenção e preparo das amostras}

As amostras foram tomadas do músculo Longissimus dorsi (contra filé), à altura da 12a costela, 24 horas após o abate. Cada amostra, de aproximadamente $15 \mathrm{~cm}$ de comprimento, foi dividida, por secção transversal ao eixo de orientação das fibras, em 5 fatias de aproximadamente $3 \mathrm{~cm}$ cada. Aleatoriamente, foram tomadas 2 fatias de cada amostra para constituírem o grupo controle, não recebendo qualquer tratamento e, em cada uma das 3 fatias restantes, foi injetada solução de $\mathrm{CaCl}_{2}$ na concentração de 100, 200 ou $300 \mathrm{mM}$. As soluções foram injetadas, com seringa manual, na proporção de $5 \%$ (v/p). Após a injeção, as fatias permaneceram à temperatura ambiente por 5 minutos para equilíbrio na distribuição salina, sendo, em seguida, pesadas novamente, embaladas a vácuo e maturadas por 14 dias em estufa BOD a $0,5^{\circ} \mathrm{C}$. Após o período de maturação as amostras foram congeladas e mantidas a $-18^{\circ} \mathrm{C}$ para posterior análise.

Do grupo controle e de cada tratamento, foram utilizadas 3 fatias para a determinação do índice de fragmentação, 3 fatias para a determinação instrumental da textura e as restantes foram utilizadas na análise sensorial.

\section{3 - Análise sensorial}

Para a análise sensorial foi utilizado um teste afetivo de preferência pareada, sendo aplicadas múltiplas comparações na mesma série de amostras [7]. As amostras foram avaliadas por um grupo de 62 provadores não treinados, selecionados ao acaso, consumidores habituais de carne bovina. Para seu preparo, a carne foi previamente descongelada por $16 \mathrm{~h}$ a $4^{\circ} \mathrm{C}$ e cozida, ainda embalada, em água fervente até atingir $70^{\circ} \mathrm{C}$ no interior, sendo essa temperatura monitorada com o uso de um termômetro de inserção. Em seguida, as amostras foram cortadas em cubos, evitando-se as porções periféricas e tecido colagenoso, e identificadas por números aleatórios de três dígitos. Assim, cada provador recebeu quatro amostras: sem tratamento, tratada com solução $100 \mathrm{mM}, 200 \mathrm{mM}$ e $300 \mathrm{mM}$ de $\mathrm{CaCl}_{2}$; para ser comparada a uma referência constituída de carne também sem tratamento. Uma das amostras sem tratamento foi introduzida entre as amostras testadas com o intuito de estimar melhor a capacidade dos provadores de detectar diferença das amostras em relação à referência.

Os provadores expressaram sua opinião escolhendo, para cada amostra, uma das seguintes opções: 1muito pior que a referência, 2- pior que a referência, 3- moderadamente pior que a referência, 4- igual à referência, 5-moderadamente melhor que a referência, 6-melhor que a referência e 7- muito melhor que a referência. Solicitou-se ainda ao provador, ao final da degustação, indicar, na ficha de resposta, a amostra que considerou mais macia. Essa resposta foi utilizada apenas como um indicativo da tendência dos provadores, uma vez que a realização de testes sensoriais analíticos, para determinação de características específicas, exige equipes treinadas [7, 8].

\section{4 - Análise do indice de fragmentação (IF)}

O índice de fragmentação foi determinado segundo a metodologia proposta por DAVIS et al. [4]. Essa metodologia analítica se fundamenta no tamanho dos fragmentos resultantes da atividade proteolítica de enzimas da carne durante o período de maturação. Uma atividade proteolítica mais intensa resulta em ligações mais fracas, gerando fragmentos menores quando uma força é aplicada e, conseqüentemente, uma menor quantidade de material retido na etapa de filtragem. Amostras de 10 gramas de carne congelada foram homogeneizadas, em rápida velocidade, em liquidificador industrial, com $50 \mathrm{~mL}$ de solução $0,25 \mathrm{M}$ de sacarose e $0,02 \mathrm{M}$ de $\mathrm{KCl}$ a $5^{\circ} \mathrm{C}$. Em seguida, esse homogenato foi filtrado através de uma peneira de $250 \mu \mathrm{m}$ de porosidade. A fração retida na peneira, constituída de fragmentos maiores que $250 \mu \mathrm{m}$, foi colocada sobre papel de filtro Whatman $\mathrm{n}^{\circ} 3$, permanecendo por $40 \mathrm{~min}$ em estufa $\mathrm{BOD}$ a $25^{\circ} \mathrm{C}$, para secagem. O peso dessa fração, após a secagem, foi determinado e multiplicado por um fator de 100. Nessa avaliação, índices próximos a 100 indicam carne muito macia e índices em torno de 600 correspondem a amostras extremamente duras, inaceitáveis ao consumidor. As amostras foram testadas em duplicata.

\section{5 - Determinação da força de cisalhamento}

A maciez das amostras foi avaliada instrumentalmente pela determinação da força de cisalhamento em Texturômetro $\mathrm{TAXT}_{2}$, equipado com célula de carne de Warner Bratzler. Foram analisados três grupos das amostras congeladas. Para isso, as amostras foram cozidas conforme descrito para análise sensorial. Após o cozimento, deixou-se resfriar a carne em estufa BOD por $4^{\circ} \mathrm{C} / 12$ horas, após o que retirou-se, de cada peça, 6 amostras cilíndricas com $1,27 \mathrm{~cm}$ de diâmetro, no sentido longitudinal em relação às fibras, de acordo com a metodologia descrita por POSTE et al. [15]. Na avaliação foi empregada a velocidade de cisalhamento de $5,0 \mathrm{~mm} / \mathrm{seg}$ e os resultados expressos como força máxima de cisalhamento, em kilogramas. 


\section{6 - Análise estatística}

Os resultados foram submetidos à análise de variância, com posterior ajuste de equações de regressão, para verificar o comportamento de cada uma das variáveis estudadas em função dos niveis crescentes e eqüidistantes de $\mathrm{CaCl}_{2}$ adicionado às amostras, através do programa estatístico SAS [20]. Na seleção das equações de regressão, as significâncias dos coeficientes dos modelos foram considerados pelo teste $t$, a $5 \%$.

\section{3 - RESULTADOS E DISCUSSÃO}

$\mathrm{O}$ aumento da concentração da solução de $\mathrm{CaCl}_{2}$ adicionada às amostras teve um efeito positivo significativo sobre a textura da carne $(\mathrm{p}<0,05)$, reduzindo a força de cisalhamento. Segundo a equação apresentada na Figura 1, para um aumento de $100 \mathrm{mM}$ na concentração de $\mathrm{CaCl}_{2}$, corresponde uma diminuição de $0,9059 \mathrm{~kg}$ na força de cisalhamento. Através dessa equação linear, 37\% da variação da força de cisalhamento das amostras é explicada pela concentração de $\mathrm{CaCl}_{2}\left(\mathrm{R}^{2}=0,37\right)$. Isso demonstra que a textura da carne resulta de uma complexa interação de fatores, sendo ainda necessários estudos para que esses mecanismos sejam melhor compreendidos. Essa dificuldade vem sendo relatada em outros trabalhos $[13,21]$ e confirma a dificuldade de estabelecer parâmetros que permitam melhorar, padronizar ou mesmo predizer a textura da carne bovina. As médias de força de cisalhamento das amostras variaram entre 5,08 e 8,22kg, sendo o menor valor correspondente às amostras tratadas com soluções de $\mathrm{CaCl}_{2}$ na concentração $200 \mathrm{mM}$. As amostras tratadas com solução 200 e $300 \mathrm{mM}$ apresentaram valores de força de cisalhamento semelhantes, próximos à faixa teórica de aceitação, cujo limite é 5,0kg [6]. LANSDELL et al. [10], adicionando solução $200 \mathrm{mM}$ na razão de $5 \%$ (v/p) à carne bovina, também observaram melhora na textura, com mínimo efeito em outros indicativos de qualidade, avaliados sensorialmente. MOURA et al. [13], avaliando o efeito da adição de soluções 200 e $300 \mathrm{mM}$ de $\mathrm{CaCl}_{2}$ à carne bovina, observaram que a maior redução da força de cisalhamento ocorreu com a concentração de $200 \mathrm{mM}$.

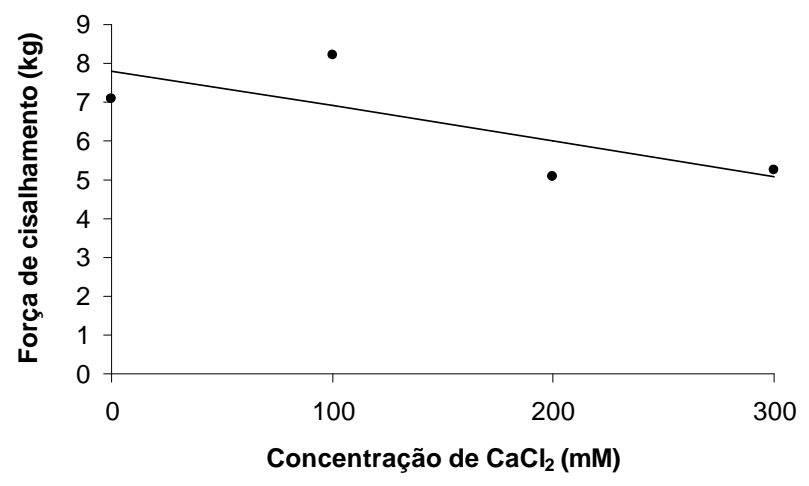

FIGURA 1. Efeito da concentração da solução de $\mathrm{CaCl}_{2}$ adicionada sobre os resultados da avaliação instrumental de textura.
A Figura 2 demonstra o efeito significativo $(\mathrm{p}<0,05)$ da concentração da solução de $\mathrm{CaCl}_{2}$ adicionada às amostras sobre as médias de Índice de Fragmentação - IF das proteínas, após a maturação das amostras. Observa-se que a intensidade de proteólise foi influenciada pela quantidade de cálcio adicionado às amostras, demonstrando a eficácia desse procedimento. Segundo a equação obtida, cada aumento de $100 \mathrm{mM}$ na concentração de $\mathrm{CaCl}_{2}$ implicou numa diminuição de 38,0667 no índice de fragmentação. Esse índice varia numa escala de 100 a 600 , onde os menores valores correspondem a uma fragmentação protéica mais intensa, resultando numa menor quantidade de fragmentos maiores que $250 \mu \mathrm{m}$, retidos na etapa de filtragem. Por considerar que a principal alteração que ocorre no tecido muscular durante a estocagem, após o abate, é a desintegração gradativa das miofibrilas, DAVIS et al. [4] estudaram diversas alternativas para estimar a fragmentação protéica de amostras de carne bovina, a fim de disponibilizar uma metodologia para medir a intensidade desse fenômeno. Dentre elas, a que demonstrou maior aplicabilidade foi a metodologia empregada neste trabalho. Empregando-se essa metodologia, os autores observaram valores variando entre 117 e 335 . As médias observadas neste trabalho ficaram entre 171 e 294, situando-se dentro dessa faixa de variação.

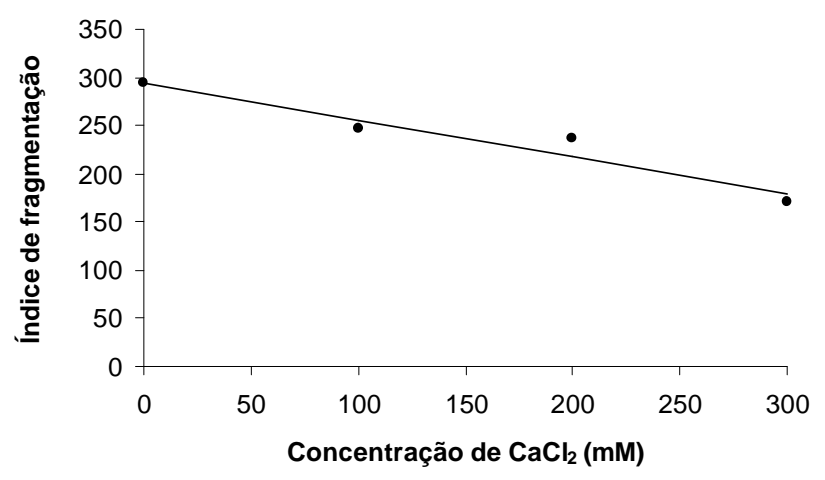

FIGURA 2. Efeito da concentração da solução de $\mathrm{CaCl}_{2}$ adicionada sobre a extensão da proteólise da carne maturada

Observou-se também que 38\% da variação do índice de fragmentação é explicada pela concentração de $\mathrm{CaCl}_{2}$ através da equação linear proposta $\left(\mathrm{R}^{2}=0,38\right)$. Esse resultado demonstra a grande quantidade de fatores que interagem em todas as reações bioquímicas da carne, o que dificulta o estabelecimento de modelos que permitam induzir, ou mesmo predizer, o comportamento de suas características relacionadas à qualidade.

$\mathrm{O}$ efeito da concentração da solução de $\mathrm{CaCl}_{2}$ sobre a aceitabilidade das amostras foi representado significativamente $(\mathrm{p}<0,05)$ por uma curva de resposta de efeito quadrático, conforme demonstrado na Figura 3. Os escores médios obtidos na análise sensorial variaram de 3,63 a 4,58 , sendo o menor escore correspondente às amostras controle, sem adição de solução de cloreto de cálcio. O maior escore correspondeu às amostras adicionadas de solução $200 \mathrm{mM}$ 
de cloreto de cálcio, o que pode ter sido decorrência de um efeito negativo da maior concentração de $\mathrm{CaCl}_{2}$ na aceitabilidade da carne. A equação quadrática apresentada explica $43 \%$ da variação do escore da análise sensorial $\left(R^{2}=0,43\right)$. Aplicando essa equação, é possível presumir que a concentração de $\mathrm{CaCl}_{2}$ que proporcionaria um valor máximo no escore de análise sensorial seria $181,14 \mathrm{mM}$. No entanto, é importante ressaltar a grande quantidade de fatores que influenciam a aceitabilidade do produto, destacandose entre eles a preferência individual dos provadores, uma vez que testes afetivos de análise sensorial são realizados com provadores não treinados. Embora BOLEMAN et al. [2] tenham relatado que a adição de solução $300 \mathrm{mM}$ à carne bovina na razão de $10 \%$ (v/p) foi efetiva na melhoria da textura, mantendo a aceitabilidade do produto, outros trabalhos [13, 14] constataram o desenvolvimento de sabor desagradável com o emprego dessa concentração de $\mathrm{CaCl}_{2}$. Com base nos resultados obtidos das fichas de avaliação sensorial, foi possivel observar que 67\% dos provadores consideraram as amostras tratadas com cloreto de cálcio mais macias do que as não tratadas, indicando o efeito positivo desse procedimento tecnológico na avaliação sensorial da textura. No entanto, $30 \%$ dos provadores consideraram a carne adicionada de solução $300 \mathrm{mM}$ pior ou muito pior que o controle, citando até mesmo um sabor alterado em alguns casos. Para as amostras tratadas com solução 200mM, essa porcentagem de rejeição diminuiu para $13 \%$. Isto é um importante indicativo de que, para alguns consumidores, essa alternativa tecnológica pode causar efeitos indesejados nas características organolépticas. Segundo KERTH, MILLER, RAMSEY [16], quantidades maiores de cloreto de cálcio promovem melhores resultados de maciez, ficando o limite máximo restrito ao sabor conferido à carne. MILLER et al. [12] avaliaram o efeito da injeção de solução $200 \mathrm{mM}$ de cloreto de cálcio em carne bovina e observaram, além do aumento da maciez, que os consumidores se revelaram dispostos a consumir carnes submetidas a esse procedimento tecnológico.

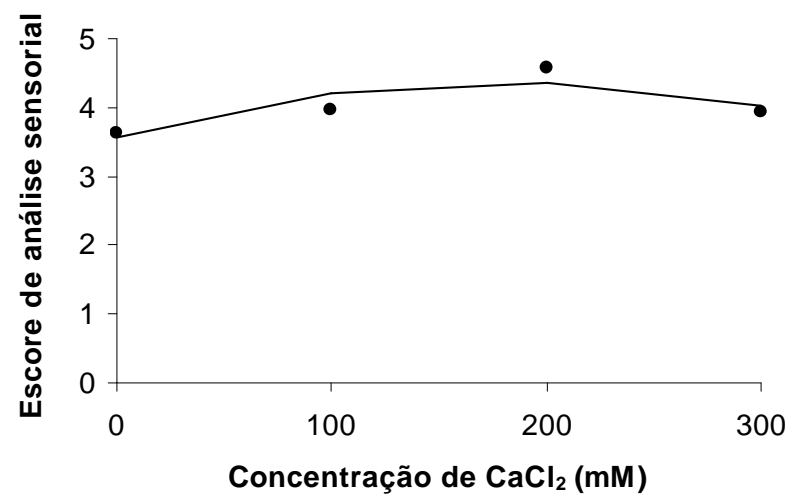

FIGURA 3. Efeito da concentração da solução de $\mathrm{CaCl}_{2}$ adicionada sobre os escores das amostras submetidas à análise sensorial.

\section{4 - CONCLUSÕES}

O aumento da concentração de cloreto de cálcio intensificou a proteólise durante a maturação, detectada pelo índice de fragmentação miofibrilar das amostras e influenciou positivamente a textura da carne, reduzindo a força de cisalhamento. O efeito da concentração de cloreto de cálcio sobre a aceitabilidade das amostras não seguiu um comportamento linear, sendo melhor representado por uma curva de resposta de efeito quadrático, cuja equação indica que a concentração mais adequada para a aplicação desse procedimento tecnológico é de 181,14mM. Os baixos coeficientes de determinação verificados em todos os modelos demonstram a grande interação de variáveis envolvidas na formação dos atributos da carne in natura, o que dificulta seu controle e padronização.

\section{5 - REFERÊNCIAS BIBLIOGRÁFICAS}

[1] BLISKA, F.M.M.; GONÇALVES, J.R. Cadeia produtiva e qualidade de carne bovina no Brasil. In: WORKSHOP SOBRE GUALIDADE DA CARNE E MELHORAMENTO GENÉTICO DE BOVINOS, 1., 1998, São Carlos. Anais..., Campo Grande: EMBRAPA - CNPGC, 1988.

[2] BOLEMAN, S.J.; BOLEMAN, S.L.; BIDNER, T.D.; Mc MILLIN, K.W.; MONLEZUN, C.J. Effects of postmortem time of calcium chloride injection on beef tenderness and drip, cooking ant total loss. Meat Science, v. 39, p. 35-41, 1995.

[3] BRASIL. Ministério da Agricultura. Decreto lei $\mathrm{n}^{\circ} 2.244$, 5 jun., 1997. Regulamento da inspeção industrial e sanitária de produtos de origem animal. Brasília, 1997. 204p.

[4] DAVIS, G. W.; DUTSON, T. R.; SMITH, G. C.; CARPENTER, Z. L. Fragmentation procedure for bovine longissimus muscle as an index of cooked steak tenderness. Journal of Food Science, v. 45, p.880$884,1980$.

[5] DRANSFIELD, E. Optimisation of tenderisation, ageing and tenderness. Meat Science, v. 36, p.105-121, 1994.

[6] FELÍCIO, P.E. Maciez da carne, fator de competitividade. DBO Rural Especial - Pecuária de Corte, p. 8891, 1995.

[7] IFT. Guidelines for the preparation and review of papers reporting sensory evaluation data. Food Technology, v. 35, n.4, p.16-17, 1981

[8] IFT. Sensory evaluation guide for testing food and beverage products. Food Technology, v. 35, n.11, p.50-59, 1981 a

[9] JOHNSON, M. H.; CALKINS, C. R.; HUFFMAN, R. D.; JOHNSON, D. D.; HARGROVE, D.D. Differences in cathepsin $\mathrm{B}+\mathrm{L}$ and calcium -dependent protease activities among breed type and their relationship to beef tenderness. Journal of Animal Science, v. 68, p. 2371- 2379, 1990.

[10] LANSDELL, J.L.; MILLER, M. F.; WHEELER, T. L.; KOOHMARAIE, M.; RAMSEY, C. B. Postmortem injection of calcium-chloride effects on beef quality traits. Journal of Animal Science, v.73, n.6, p.17351740, 1995.

[11] LAWRIE, R.A. 1998. Ciencia de la carne. Acribia, Zaragoza.

[12] MILlER, M.F.; HUFFMAN, K.L.; GILBERT, S.Y.; HAMMMAN, L.L.; RAMSEY, C.B. Retail consumer 
acceptance of beef tenderized with calcium chloride. Journal of Animal Science, v. 73, p.2308-2314, 1995.

[13] MOURA, A.C.; FILHO, A.L.; NARDON, R.F.; RAZOOK, A.G. Efeito da injeção de cloreto de cálcio pós-morte e tempo de maturação no amaciamento e nas perdas de cozimento do músculo Longissimus dorsi de animais Bos indicus e Bos taurus selecionados para ganho de peso. Revista Brasileira de Zootecnia. v.28, n.6, p.13821389, 1999.

[14] MORGAN, J.B.; MILLER, R.K.; MENDEZ, F.M.; HALE, D.S.; SAVELL, J.W. Using calcium chloride injection to improve tenderness of beef from mature cows. Journal of Animal Science, v.69, n.11, p.4469-4476, 1991.

[15] POSTE, L.M.; BUTLER, G.; MACKIE, D.; AGAR, V.E.; THOMPSON, B.K. Correlations of sensory and instrumental meat tenderness values as affected by sampling techniques. Food Quality and Preference, v. 4, p.207214,1993

[16] KERTH, C.R.; MILLER, M.F.; RAMSEY, C.B. Improvement of beef tenderness and quality traits with calcium chloride injection in beef loins 48 hours postmortem. Journal of Animal Science, v. 73, p.750-756, 1995.

[17] KOOHMARAIE, M. WHEELER, T.L.; SHACKLEFORD, S.D. Maciez da carne: Regulação e Predição. DELTA G, 1994 .
[18] KOOHMARAIE, M. WHEELER, T.L.; SHACKLEFORD, S.D. Effect of prerigor freezing and postrigor calcium chloride injection on the tenderness of callipyge longissimus. Journal of Animal Science, v. 76, p.1427-1432, 1998.

[19] ROUSSET-AKRIM, S.; GOT, F.; BAYLE, M.C.; CULIOLI, $\mathrm{J}$. Influence of $\mathrm{CaCl} 2$ and $\mathrm{NaCl}$ injections on the texture and flavour of beef. International Journal of Food Science and Technology, v.31, p.333-343, 1996.

[20] SAS INSTITUTE INC. Sas User'S Guide: Statistics, Ver 6. 12 th. SAS INSTITUTE INC., Cary, NC, 1995.

[21] SMULDERS, F.J.M.; MARSH, B.B.; SWARTZ, D.R.; RUSSELL, R.L.; HOENECKE, M.E. Beef tenderness and sarcomere length. Meat Science, v.28, p. 349-363, 1990.

\section{6 - AGRADECIMENTOS}

Os autores agradecem à Prof. Dra. Sílvia Helena Venturoli Perri pela realização da análise estatística e à FAPESP - Fundação de Amparo à Pesquisa do Estado de São Paulo - pelo apoio financeiro. 